Portland State University

PDXScholar

1990

\title{
The creation of a core vacabulary for initial lexicon selection for nonspeaking preschool children
}

\author{
Lillian May More \\ Portland State University
}

Follow this and additional works at: https://pdxscholar.library.pdx.edu/open_access_etds

Part of the Communication Commons, and the Linguistics Commons Let us know how access to this document benefits you.

\section{Recommended Citation}

More, Lillian May, "The creation of a core vacabulary for initial lexicon selection for nonspeaking preschool children" (1990). Dissertations and Theses. Paper 4107.

https://doi.org/10.15760/etd.5991

This Thesis is brought to you for free and open access. It has been accepted for inclusion in Dissertations and Theses by an authorized administrator of PDXScholar. Please contact us if we can make this document more accessible: pdxscholar@pdx.edu. 
AN ABSTRACT OF THE THESIS OF Lillian May More for the Master of

Science in Speech Communication with an emphasis in Speech-Language Pathology presented April 30, 1990.

Title: The Creation of a Core Vocabulary in Initial Lexicon Selection for Nonspeaking Preschool Children

APPROVED BY THE MEMBERS OF THE THESIS COMMITTEE:

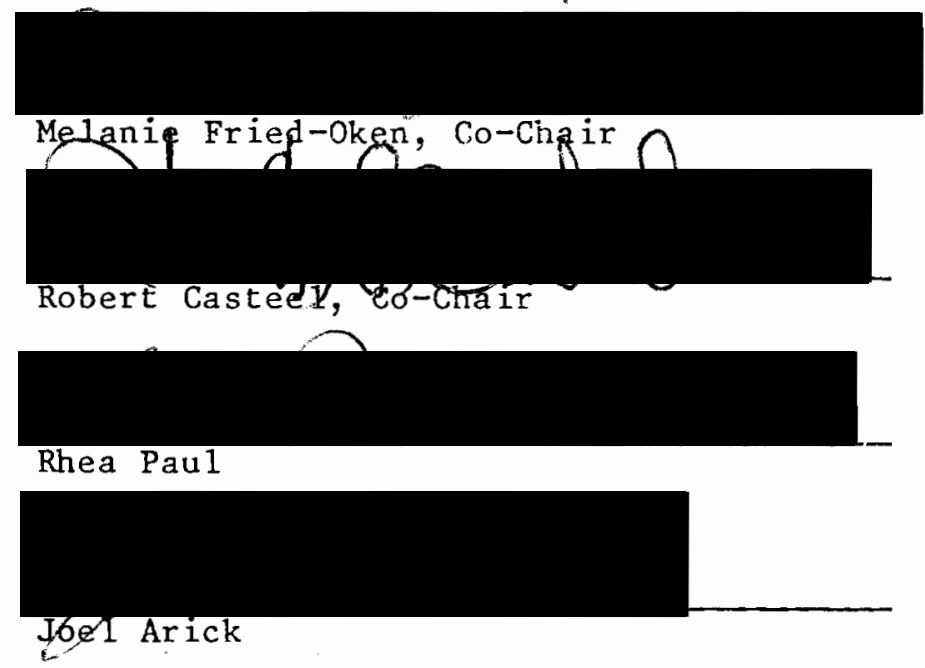

The selection of the initial lexicon is one of the most important decisions made in the implementation of augmentative communication systems with preliterate, nonspeaking preschool children. If a communication aid is to be adopted by a child, the words available on the device must be interesting to the child and encourage communication. The vocabulary must allow for cognitive growth and foster language development. Ideally, a lexicon would be customized for each nonspeaking child's particular interests, vocabulary needs and 
developmental leve1. The reality is that vocabulary selection is a difficult and time consuming process. Parents and clinicians do not always have the time or expertise to develop an individualized lexicon and must depend on a prepared list. These lists are not always appropriate for preschool children. A carefully developed core vocabulary could serve as a framework for the initial lexicon and would ensure that the words available to the children promoted communication and language growth. This would allow caregivers to concentrate on the smaller individualized portion of the lexicon.

The purpose of this study was to compare the words generated by the caregivers of nonspeaking, preschool children to words present in the lexicons of communication aids suitable for these children. It sought to determine the feasibility of a core vocabulary for this population and if lists on communication aids met this need. The subjects were 15 nonspeaking, nonambulatory children with Cerebral Palsy between the ages of 3.0 and 6.0 years. The children were reported to have within-normal hearing and cognitive skills. The parents and clinicians were asked to 1 ist the 100 words that they felt were most important for their child to communicate in his or her daily environment. One large composite 1 ist was created from the 30 individual 1ists. A 1ist of 293 words was created from words which appeared on 3 or more respondent lists. Each individual 1 ist was compared to this composite list and the number of common words from the individual lists and the composite list were counted. Similarity was calculated as a percent. The agreement between individual 1 ists and the respondent composite list ranged from 65 to 89 percent, with a mean of 79 
percent. These results indicate that the parents and clinicians of nonspeaking children chose similar vocabulary and suggests that the development of a core vocabulary is indeed possible.

The respondent composite list was then compared to the lists from communication aids which were developed or suitable for use with preschool children. These published lists were: vocabulary from the Self Talk communication board overlays, Levels 1 and 2; Core Picture Vocabulary; Minspeak starter vocabulary; and vocabulary from the programmed levels of the VOIS 160 speech output device. The data base was queried to perform a series of pairwise comparisons between 1ists. This query provided three figures: the percentage of the words from the first list which appeared in the second list, the percentage of words from the second list which appeared in the first list, and the number of common words between the two lists. A percent agreement between each set of lists was calculated by dividing the number of common words into the number of words on both lists.

The results of this set of comparisons indicated that the percent agreement between list pairs ranged from 7 to 25 percent. This low overall agreement was, in part, the result of the differences in list sizes, which ranged from 110 words on the Self Talk list to 1,253 words on the VoIS 160 list. A closer analysis of the pairwise comparisons showed that large proportions of the smaller lists were actually present in the larger lists. For example, while the percent agreement between the Self $\mathrm{Talk}$ and respondent-generated composite list was only 24 percent, 88 percent of the 110 -word Self Talk 1 ist 
was contained within the 293-word respondent composite list. With the exception of the Minspeak list, which was not similar to any of the smaller lists, a large proportion of the smaller lists was contained in the larger lists. It is important to note that none of the smaller lists was completely contained within the larger lists.

In the final comparison, one composite list was created from the 2,219 words appearing across all 5 lists. Of a list of 1,336 unique words, a core of 30 words appeared on all of the 1ists. Eighthundred-eleven words appeared on ly once across all five lists.

The high agreement between words selected by the caregivers of nonspeaking preschool children indicates that the use of a core vocabulary is indeed feasible. A comparison between the respondent composite list and the lists currently available on communication aids for use with nonspeaking children indicates that the lists differ in size and content. No list completely meets the vocabulary needs as determined by the adults or can be considered suitable as a core vocabulary. Both the 293-word respondent composite list and the core of 30 words which occurred across all 5 communication aid lists may be useful in the development of a core vocabulary for nonspeaking, preschool children. 
THE CREATION OF A CORE VOCABULARY FOR INITIAL LEXICON SELECTION FOR NONSPEAKING PRESCHOOL CHILDREN

by

Lillian May More

A thesis submitted in partial fulfillment of the requirements for the degree of

\author{
MASTER OF SCIENCE \\ in \\ SPEECH COMMUNICATION: \\ with an emphasis in \\ SPEECH-LANGUAGE PATHOLOGY
}

Portland State University

1990 
TO THE OFFICE OF GRADUATE STUDIES:

The members of the Committee approve the thesis of Lillian May More presented April 30, 1990.

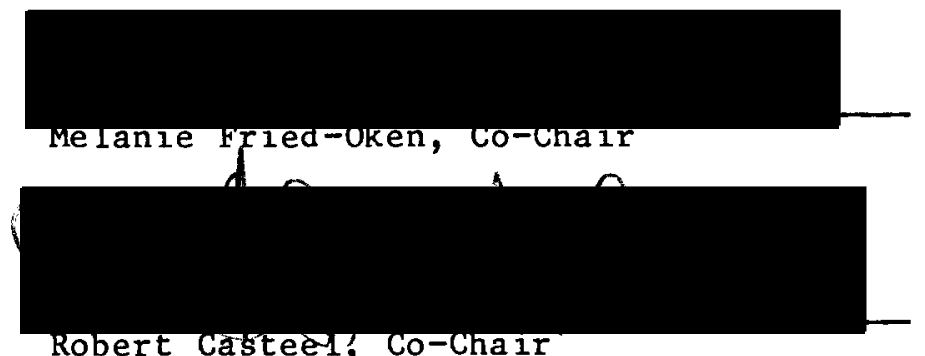

Robert casteè, Co-chair
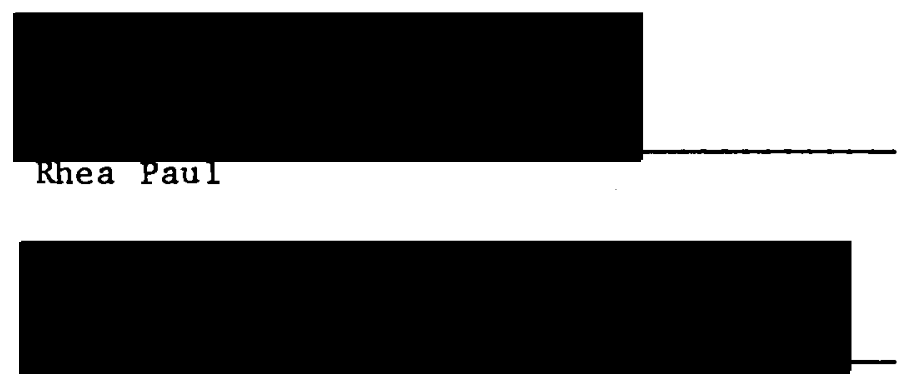

Joex Arick

APPROVED :

Theodore G. Grove, Chair, Department of Speech Communication

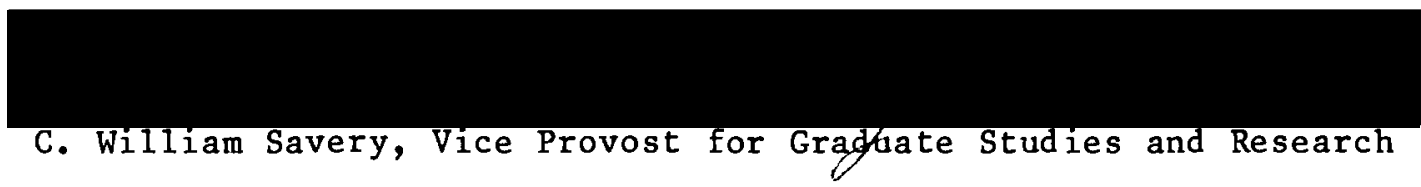




\section{ACKNOWLEDGEMENTS}

Over the past two years I have had the support and encouragement of many people. I would especially like to thank my mentor, Dr. Melanie Fried-Oken, for allowing me to participate in her ongoing research in augmentative and alternative communication. I would also like to thank my advisor, Dr. Robert Casteel, and the other members of my thesis committee, Dr. Rhea Paul and Dr. Joel Arick. Most of a11, to my family and friends who listened during the highs and the lows of this endeavor--thank you! 
TABLE OF CONTENTS

PAGE

ACKNOWLEDGEMENTS . . . . . . . . . . . . . . . . . . iii

LIST OF TABLES . . . . . . . . . . . . . . . . . . . vi vi

LIST OF FIGURES . . . . . . . . . . . . . . . . . . vii

CHAPTE R

I INTRODUCTION AND STATEMENT OF PURPOSE . . . . . . . . 1

Introduction ............... . . 1

Statement of Purpose .. . . . . . . . . 4

Definition of Terms............ 5

II REVIEW OF THE LITERATURE • . . . . . . . . . . • . 6

Lexicon Selection in Language Intervention . . . 6

Lexicon Selection for Sign Lexicons... . . . 8

Lexicon Selection in AAC ........... . 11

Vocabulary Needs of Nonspeaking Children

Methods of Vocabulary Selection

Summary . . . . . . . . . . . . 20

II METHODS . . . . . . . . . . . . . . . 21

Subjects . . . . . . . . . . . . . 21

Materials . . . . . . . . . . . 21

Procedures ................. 22

Data Analysis . . . . . . . . . . . . 25 
IV RESULTS AND DISCUSSION . . . . . . . . 27

Results............... . 27

Discussion ............... 35

$\mathrm{V}$ SUMMARY AND IMPLICATIONS ............ 50

Summary . . . . . . . . . . 50

Implications ........... . . 53

Clinical Implications

Research Implications

REFERENCES

APPENDICES

A VOCABULARY FORMS TO BE COMPLETED BY PARENTS AND

CLINICIANS . . . . . . . . . . . 63

B INFORMED CONSENT FORM . . . . . . . . . . 69

C COVER LETTER WITH INSTRUCTIONS FOR PARENTS AND

CLINICIANS . . . . . . . . . . . . 71

D RESPONDENT COMPOSITE LIST ........... 73 


\section{LIST OF TABLES}

TABLE

PAGE

I Name and Size of Communication Aid Lists . . . . . . 30

II Pairwise Comparisons Between Communication Aid Lists . . 31

II Number of Words in Each Commonality Grouping From Comparison of Five Lists . . . . . . . 35

IV Words Which Appeared on Al1 Five Communication Aid Lists................ 47 


\section{LIST OF FIGURES}

1 Percent of Individual Respondent Lists Found in Respondent Composite List . . . . . . . . . 29

2 Pairwise Comparisons Among All Communication Aid Lists . 32 


\section{CHAPTER I}

\section{INTRODUCTION AND STATEMENT OF PURPOSE}

\section{INTRODUCTION}

Careful planning is required for the successful implementation of an augmentative and alternative communication (AAC) system for a child with severe physical disabilities and a severe expressive communication impairment. An AAC system must provide for a child's basic communication needs, such as requests for food or drink, and for conversational needs such as questioning, demanding, refusing, and labelling. It should be integrated with other aspects of a child's life so that it is useful with a variety of communication partners (i.e., brothers and doctors), in various communication settings (i.e., playground and bedtime) and with different physical positions (i.e., in a whee lchair or in bed). The AAC system should allow and foster cognitive and linguistic growth, and be motivating to the child and others (Vanderheiden and Lloyd, 1986).

Vanderheiden and Lloyd (1986) divide an AAC system into three components :

1. symbols and language representation;

2. transmission techniques, or means of sending a message to the message receiver;

3. strategies for increasing speed, access to the language, and the effectiveness of communication. 
Although all aspects of an AAC system require careful consideration, the selection of an appropriate lexicon is critical in establishing a functional communication system. The vocabulary selected will affect the child's ability to learn language and interact with others. Language develops out of a child's attempts to control his or her environment (Bates, 1976). For example, 1abels emerge from the early routines of giving and showing. Nonspeaking children, however, have limited ability to manipulate their environments, so the basic communication acts may not develop (Carlson, 1981). They cannot babble or experiment with the sounds and words they hear; therefore, expressive language does not emerge spontaneously. Speaking children talk about their world: familiar toys, people, pets, food, clothing, places, and routines (Owens, 1988). Nonspeaking children depend entirely on the sets of words selected for them by their caregivers (Carlson, 1981). Since only a few of the words of a language can actually be included on an initial AAC system, the children are restricted in the number and the type of words available for early expressive language. If the children do not have the flexibility to say what they want or need to say, they may not understand the reason to communicate, and despite careful planning on other aspects, the entire system will fail.

Vocabulary selection, to this point, has been a trial and error process based primarily on clinical experience and intuition (Carlson, 1981). Yorkston, Dowden, Honsinger, Marriner, and Smith described it as "the process of choosing a small list of appropriate words or items from a pool of all possibilities" (1988, p. 201). As such, vocabulary 
selection can be a difficult and time-consuming process. Research on word usage of nonspeaking adults indicates, however, that diverse groups of nonspeaking people actually use similar vocabulary (Beuke1man, Yorkston, Poblete and Naranjo, 1984). Certain words, either because of high frequency of use or utility to the individual, appear on most nonspeakers' lexica. These words form a core vocabulary. The words which are unique to a particular individual in particular situations can be considered a fringe vocabulary. It has been suggested that the development of a carefully selected core lexicon from which to choose words would facilitate the process of vocabulary selection. Such a core has been created for nonspeaking adults (Yorkston et al., 1988).

A core vocabulary does not exist for nonspeaking children. The 1 ists which have served as sources for vocabulary selection have not been empirically based or socially validated. These lists are often based on frequency of occurrence, and many words which are functionally important to nonspeaking individuals are not present (Yorkston et al., 1988). Other lists have been based on normal language development (Fristoe and Lloyd, 1981). This assumes nonspeaking children and normally developing children learn language in the same way. It also assumes that nonspeaking children have the same vocabulary needs as speaking children. Both assumptions may be incorrect. Admittedly, some lists used in lexicon selection are clinically based and have been developed by speech-language pathologists who work with nonspeaking individuals. While these lists are used in lexicon selection for children, they may not have been developed or intended for 
children and may not address children's specific vocabulary needs. While speech-language pathologists are knowledgeable in communication patterns and language development, lexicons should also include words selected by the parents and teachers of nonspeaking children. These are the people who are with the children for long periods of time and for a variety of activities. They are aware of the children's personalities, needs and daily routines. They are in a position to predict what the children might want or need to say. It is possible that the words the caregivers select are more appropriate for nonspeaking children than the words which appear on published 1 ists or on communication devices.

\section{STATEMENT OF PURPOSE}

The purpose of this study was to compare the words selected by the caregivers of nonspeaking preschool children to the words available on different communication aids. It sought to determine the feasibility of using a core vocabulary for this population and if any currently available lists were suitable for this purpose. It involved creating a composite list from the individual vocabulary lists generated by the parents and clinicians of nonspeaking, nonambulatory three- to six-year-old Cerebral Palsied children and comparing this composite list to the vocabularies presented on communication aids. To accomplish this goal, the following research questions were posed:

1. What were the common words selected by the parents and clinicians of nonspeaking three- to six-year-old Cerebral Palsied children? 
2. How similar was the vocabulary appearing on communication aids which were developed or suitable for use by nonspeaking children?

3. What were the common words from the respondent-generated composite list and the vocabulary on the communication aid 1 ists?

\section{DEFINITION OF TERMS}

The following terms were used as operational definitions for this study :

1. Augmentative and Alternative Communication (AAC). Refers to any strategy, technique, or device developed specifically to supplement or replace oral speech for individuals with expressive language impairments (Vanderheiden and Yoder, 1986).

2. Communication Aid. An object or device that helps an individual communicate. These include communication boards as we 11 as mechanical and electronic devices (Vanderheiden and Yoder, 1986).

3. Communication Station. A system with a number of different components to meet an individual's communication needs. It includes an integration of the symbols, aids, techniques and strategies that an individual uses in a number of different communication contexts (Vanderheiden and Lloyd, 1986).

4. Core Vocabulary. A set of words which, because of frequency of use or utility to the user, appears on most communication devices (Yorkston et al., 1988).

5. Nonambulatory. A condition where the individual is unable to use independent ambulation as the primary mode of mobility.

6. Nonspeaking. A condition where the individual is unable to use oral speech as the primary mode of communication.

7. Published Vocublary Lists. Single word vocabulary lists which have been developed for and mapped onto communication aids. 
CHAPTER II

REVIEW OF THE LITERATURE

This study looks at initial expressive vocabulary selection for nonspeaking children of reported normal or near-normal cognitive skills. As there is no body of literature which deals with vocabulary selection for this specific population, this chapter will review research on initial lexicon selection from three bodies of literature: intervention for early language disorders, sign lexicons for mentally retarded individuals, and vocabulary selection for augmentative and alternative communication ( $A A C)$.

\section{LEXICON SELECTION IN LANGUAGE INTERVENTION}

Language development follows a predictable pattern. Children tend to learn language in the same general order and reach developmental milestones at about the same age. Not only does language development occur in the same order and rate, children of a similar developmental level seem to use similar words. Nelson (1973) generated a list of the first 50 words produced by normally deve1oping, speaking children. A recent study by Beukelman, Jones, and Rowan (1989) also looked at the expressive vocabulary of preschool children. Three-thousand-word language samples were collected from six four- and five-year-old children in their preschool classrooms. 
The frequency and commonality of use for each word was calculated. The analysis showed that each child used from 404 to 468 different words within their 3,000-word sample. Two-hundred-fifty words were used more than once (an occurrence of at 1east .5 per 1,000 words). Further analysis showed a core of the 25 most frequently occurring words accounted for 45 percent of the words in the total sample and a core of 250 words accounted for 85 percent of the sample. This ind icates that children do use similar words.

Our knowledge of the invariant nature of language development has been applied to both the diagnosis and intervention of language-disordered children. Knowing the order that different forms appear and the types and number of words that children typically use at a certain age or developmental leve 1 allows us to make judgments on the degree or nature of the delay. For example, vocabulary checklists based on normal language development are used as screening tools to accurately assess language production (Reznick and Goldsmith, 1989; Rescorla, 1989). Normal language models can also help target appropriate language intervention. Holland (1975) believed that intervention with language-disordered children should parallel normal language acquisition. She suggested that since normal children did not use words in the same way as adults, and spoke "childrenese," the vocabulary chosen for intervention with delayed children should be based on the words that children use. Since the initial lexicon must teach children that words are useful to communicate, she suggested including words and symbols of things that were important to the child and words of objects or events in the "here and now." Holland suggested that early 
single-word utterances were not simply labels and probably represented complex ideas. To allow for this, and to maximize opportunities for the child to communicate, she suggested limiting the size of the initial lexicon but using words that had more than one meaning. Based on these considerations, Holland generated a 35-item initial lexicon for language intervention. This lexicon included general vocabulary as we 11 as words specific to the individual child.

Lahey and Bloom (1977) also described a first lexicon for intervention with language-disordered children. They postulated that language learning was the process of inducing the relationship between an idea, a word, and the communication of that idea. In other words it was learning the relationship between form, content, and use. A11 three should be considered in the selection and organization of the initial lexicon. While Lahey and Bloom agreed with Holland's (1975) decision to use words which were both important to the child and concrete, they added three considerations for word selection. The first lexicon should contain words which were easily demonstrated nonlinguistica11y. To increase the potential for functional communication, it should also contain words which could be used in many situations. Finally, they recommended that the words be organized, according to form, in categories which included rejection, nonexistence, disappearance, actions, and attributes.

\section{LEXICON SELECTION FOR SIGN LEXICONS}

Sign language is often used as a supplement to spoken language for severely handicapped learners who have failed to learn functional 
speech (Reichle, Williams, and Ryan, 1981). The decision to teach manual signing to a child requires decisions about which signs to teach first. Fristoe and Lloyd (1980) suggested that the development of an initial lexicon should involve more than compiling lists of useful words. They used normal language development as the model to develop an initial expressive sign lexicon for mentally retarded and autistic individuals with expressive impairments. They compiled a pool of signs which appeared frequently in the vocabularies found in a number of different manuls designed for use with severely handicapped individuals. They then examined each sign according to the developmental guidelines developed by Holland (1975) and Lahey and Bloom (1977). Fristoe and Lloyd suggested that clinicians consider both language acquisition and the needs and wants of the specific individual. They suggested that clinicians should look at what was important to all children of a certain stage of cognitive development but also consider what was important to the individual child. Fristoe and Lloyd based their initial lexicon on the single-word stage of development of speaking children and selected a 50-word vocabulary because of the tendency of speaking children to form two-word utterances at this milestone. Fristoe and Lloyd suggested that relationa 1 words which were less specific increased children's potential for communication in a variety of situations and should form the bulk of the lexicon. Substantives, the words that referred to particular objects or categories, could be chosen with regard to each child's specific needs. 
Karlan and Lloyd (1983) suggested that vocabulary selection alone did not ensure the successful acquisition of communicative skills. They suggested functional communication could be enhanced by using a behavioral-remedial strategy for vocabulary selection. This involved making an inventory of the individual's environment and then basing sign selection on the individual's preference, basic needs, frequency of occurrence, and functional utility of the item. Karlan and Lloyd questioned the communicative usefulness of the lexicon proposed by Fristoe and Lloyd (1980). They examined the vocabulary from Fristoe and Lloyd's developmentally based sign lexicon and additional items which Fristoe and Lloyd had rejected as developmentally inappropriate. The parents, teachers, and speech pathologists of severely handicapped children and adolescents rated each word as "essential," "useful," "could be useful," or "of no value." This process of social validation supported Fristoe and Lloyd's initial lexicon. Most of the words in the lexicon were rated as useful or essential and none were considered to be of no value. Even the items not included in Fristoe and Lloyd's developmentally based lexicon were perceived as important for communication by the caregivers. Karlan and Lloyd suggested this demonstrated that a combination of functional-remedial and developmentally based strategies could be used successfully for vocabulary selection.

The selection of initial sign lexicon for severely handicapped learners was also discussed by Reichle, Williams and Ryan (1981). They suggested that when choosing an initial lexicon the clinicians must look at familiarity and representational level of the signs, 
their motoric complexity, and their functional utility. The initial lexicon should be comprised of signs which the child could understand and imitate. The authors stressed that in addition to the cognitive and motoric abilities of the individual, the clinician should also consider the functional utility of each sign. Signs with functional utility were those that would be used frequently, were associated with reinforcing objects or events, and could be used with a number of people and in a variety of situations. These researchers suggested it

was inappropriate to use vocabulary lists based on normal language development for generating initial sign lexicons because the signs for these words may have low iconic value and may be motorically difficult. They also suggested that the vocabulary used by normally developing children may be inappropriate for severely handicapped learners: the words selected should be specific to a particular individual's wants and needs.

\section{LEXICON SELECTION IN AAC}

\section{Vocabulary Needs of Nonspeaking Children}

Vocabulary selection in augmentative and alternative communication (AAC) has traditionally been "needs" related (Lowe, 1988). Most of the words or symbols on communication devices were chosen by the caregiver to facilitate meeting the child's basic physical needs. Carlson (1981) maintained that needs-related vocabularies were inappropriate to children's personalities and development. She suggested that vocabularies chosen by caregivers were made up of those words the adult needed to have the children express, not the words 
which would have naturally emerged. In other words, a speaking child might choose a completely different set of words to express the same needs. For this reason, Carlson suggested that the words chosen for an AAC system should be at an appropriate developmental leve1, within the child's experience, and express things which interested the child. Porter (1987) also believed that the initial words should be reinforcing for the child, not just the adult. She said it was important to choose words which could be reinforced immediately by the message receiver. Children's use of the words could be reinforced by the presentation of that object, activity, or person. The children would learn that communication was useful and as such would continue to use their AAC systems.

Most researchers and clinicians agree that the initial lexicon must be developmentally appropriate, but there is some disagreement as to the degree in which it should reflect the language use of normal children (Fristoe and Lloyd, 1980; Wilson, 1980; Carlson, 1981; Blau, 1983; Reichle, Williams and Ryan, 1981). Some researchers have used normal language acquisition as the model for lexicon selection (Fristoe and Lloys, 1980; Wilson, 1980). Others, such as Harris and Vanderheiden (1980), suggest that while language appears in an invariant sequence in speaking children, it may emerge at different rates and in a different order for nonspeaking children. A study by Blake-Huer (1980) which compared the receptive and expressive language development of speakers and nonspeakers indicated that speaking and nonspeaking children matched in age equivalency followed similar developmental sequences in acquiring receptive and expressive language 
skills. Even so, Blau (1983) stressed that it was wrong to assume an atypically developing child would follow a typical sequence of interactional and linguistic development. She claimed that vocabulary selection based strictly on normal development did not fit the nonspeaker's unique experiences and because of physical limitations different words were important to nonspeaking children. Reichle, Williams, and Ryan (1981) supported Blau's conjecture that words used frequently by normally developing children were not appropriate for a11 children.

Methods of Vocabulary Selection

To this point in the evolution of augmentative and alternative communication, word selection has been based on case histories and clinical intuition. There is no standard method for selecting vocabu1ary. Wilson (1980) believed that clinicians should consider four different factors: the individual, his or her environment, the limitations and capabilities of the AAC system, and normal language acquisition. She suggested that by considering these four components, clinicians could create vocabularies specific to individual children. Blau (1983) proposed that the needs and capabilities of the child, the constraints of the AAC system, and developmental data should all be considered. She referred to this approach as a "functionally based nesting mode $1 "$ because the clinician considered each factor in relation to the others in order to develop a vocabulary which was unique to the child's needs. She suggested that specific considerations in word selection were: determining words which the nonspeaker 
considered important, words which the primary caregivers considered important, words which reflected events in the child's life, words which reflected preference or dislike, words which reflected basic needs and emotion, and words the teacher or speech pathologist felt had high functional value.

Use of Observation and Interviews. Several authors have suggested a more formal approach to word selection (Carlson, 1981; B1au, 1983; Meyers, Liddicoat, and Anderson, 1984; Porter, 1987; Lowe, 1988). Porter (1987) and Meyers et a1., (1984) suggested that observation and interviews should play a major role in the word selection process. Children should be observed in multiple communication contexts and while interacting with their primary caregivers. Interviewing parents, teachers, therapists, and friends of nonspeaking children may also provide key information to children's specific communication needs (Meyers et a1., 1984). Meyers and her associates (1984) grouped communication needs into four areas: school, recreation, basic physical needs, and feelings. Caregivers selected words from each area.

Carlson (1981) suggested that parents and clinicians should observe children in their immediate environments when choosing vocabulary, and consider the objects and activities that the children either participated in or witnessed. She developed a format in which the parents observed their children in a number of settings and then compiled a pool of possible vocabulary items. The speech pathologist selected those words which were within the child's experience and of interest to the child. Extra words in the pool were set aside to use 
when the child was ready for a larger or more varied lexicon. Carlson claimed that this process was open ended and sensitive to developmental and environmental changes.

Karlan and Lloyd (1983) stated that initial lexicon selection was usually based on one of two distinct processes: developmental considerations and what they termed "functional-remedial logic." The functional-remedial approach involved developing a word pool based on the individual's preferences, basic needs, frequency of occurrence of a word, and its functional utility in different situations. It required that the clinician make an inventory of the client's environment to determine which words were needed. This included identifying activities, places, objects, and people that the child encountered. By observing the individual's reaction to different words, the clinician could determine word preference. If this was not possible, the clinician should consider the amount of time the individual spent in each different activity and choose words accordingly.

Lowe (1988) enlisted the help of the parents, speech pathologists, and teachers of six nonspeaking children in order to compare three methods of vocabulary selection. Informants were asked to complete a vocabulary checklist where they checked off the words they felt were essential or useful to the children. They then completed a categorical interview in which they identified vocabulary according to categories. For example, they 1 isted words in categories such as people, activities, actions, and feelings. In the final selection process, a "blank page" approach, the informants simply listed their own choices for vocabulary items. An analysis of the resultant 
lexicons showed that while the checklist yielded the most words, the blank page yielded the most unique words. The informants rated the checklist as the most satisfactory, fastest, and easiest to complete of the three processes. Lowe noted, however, that the informants tended to select all or most of the words on the checklist. She suggested that the informants may have felt that by choosing many words they were better able to cover their children's needs and wants. She also suggested the informants may have felt obligated to choose a large number of words. For these reasons, the vocabulary on the checklist may not be a completely valid tool for initial lexicon selection. Overall, the parents and teachers had more difficulty than the speech-language pathologists with all of the selection tools. Because each informant provided some unique information, however, Lowe concluded that it was important to include them in the vocabulary selection process. Since only 25 percent of the words selected for each subject were actually unique, Lowe suggested that a core vocabulary which supplied most of the words could be utilized. Interviews with parents, siblings, teachers, and peers could be used to choose words which were unique to the individual child.

Use of Core Vocabularies. The need for individualization of lexicons has been stressed both in the research on vocabulary needs for nonspeaking children and on methods of vocabulary selection. Recent research in the field, however, has focused on the use of core vocabularies. A core vocabulary consists of words which, because of high frequency of use or utility to the individual, are included on most AAC systems (Yorkston et al., 1988). For literate children or 
adults who type messages in a letter-by-letter manner, core vocabularies programmed into the communication aids can greatly increase the speed of message transmission (Beukelman et a1., 1984). With preliterate children, the use of core vocabularies can simplify the vocabulary selection process and ensure the lexicon includes a variety of developmenta11y appropriate words. The development of a core vocabulary for preliterate children is supported by many clinicians (Wilson, 1980; Blau, 1984; Meyers et a1., 1984). Wilson (1980) suggested that because certain concepts and needs are universal, vocabularies can overlap to a degree. This view was supported by Meyer's research (Meyers et a1., 1984). Blau (1984) suggested that the lexicons in intervention manuals were useful for vocabulary selection, but added that because nonspeakers are so diverse, no single list can adequately cover all their vocabulary needs. She suggested that the initial lexicon could be a combination of preselected or core items and words specifically selected for the individual.

Specific research on the development of a core vocabulary has been conducted on adult nonspeaking populations. Beukelman, Yorkston, Poblete, and Naranjo (1984) based their vocabulary research on the premise that similar vocabularies developed for a number of nonspeaking individuals would decrease the time and effort needed to completely individualize lexicons. To determine the feasibility of core vocabularies for a similar population, five literate, nonspeaking adults were asked to save the output of their Canon Communicator portable tape typewriters for a 14-day period. The vocabulary of each subject was analyzed for number of words and frequency of occurrence. 
The 500 most frequently occurring words of each subject were computed and compared. The analysis of this vocabulary showed that users' word lists were all very similar. Composite lists of the most frequently occurring words across all subjects were also created and the proportion of the total communication sample which could be expressed by different composite lists was computed. This analysis indicated that an average of 35 percent of the total sample could be communicated with a 25-word list, and each increase of 25 words increased the amount of the sample which could be expressed. While a 500-word composite list was sufficient to express 80 percent of what the speakers said, only 32 percent of their complete utterances could be expressed by this 1 ist. The 500 -word 1 ist represented a large proportion, but not all, of the users' total communication. The researchers concluded that it was plausible to use a core vocabulary for adult nonspeakers. While some individualization would be necessary, composite or core lists would facilitate vocabulary selection and make communication more efficient.

A more recent study compared the lexicons of nine nonspeaking adults to a number of published vocabulary lists (Yorkston, Dowden, Honsinger, Marriner, and Smith, 1988). The study first looked for similarities and differences among the standard lists to determine to what degree different standard lists could be used for vocabulary selection. The analysis showed that the standard lists differed in size and content. The standard lists were then compared to the lexicons of the nonspeakers. This comparison showed that there was very little agreement between the users' lexicons and any of the standard 
1ists. There were, however, some similarities among the user lists. A pairwise comparison of the user lists showed overlaps ranging from 5 to 51 percent. A series of composite lists was created for both the user and standard lists. A comparison of the individual and composite user 1 ists indicated that 70 percent of the user lists could be derived from a 744-word user composite 1ist. The authors suggested composite or core vocabulary lists from carefully selected populations of similar individuals could be used for word selection for other nonspeaking individuals. More specific words, or the fringe vocabulary, would be selected for each individual through environmental inventories, communication diaries and interviews.

A case study by Yorkston, Honsinger, Dowden, and Marriner (1989) looked at vocabulary selection for a 36-year-old woman. A lexicon was selected for the woman through an environmental inventory which generated word possibilities, a communication diary in which communication partners recorded the words used in interactions, and a review of published vocabulary lists. A 1 ist of 240 messages was developed. This lexicon was compared to 11 published vocabulary lists to assess the usefulness of different lists as vocabulary sources. The comparisons showed that none of the 1 ists contained all of the words considered important by the woman. While the larger lists contained a greater portion of the woman's lexicon, no list was sufficient to provide for all of her vocabulary needs. While standard 1 ists cannot be used exclusively, the authors stressed that standard lists are an important vocabulary source, and the review of appropriate 
lists can increase the efficiency of vocabulary selection by allowing the clinician to review a large number of words.

\section{SUMMARY}

A review of the literature showed that there is no standard or systematic means to select vocabulary for the elementary communication aids of nonspeaking, physically disabled children. The research suggests that the development and use of core vocabularies facilitates vocabulary selection for adults and would be beneficial for initial vocabulary selection for preliterate children. While core vocabularies have been created for adult nonspeakers and older children who have already acquired language (Beukelman et a1., 1984; Yorkston et al., 1988), there is no empirical data to confirm whether this lexicon is suitable for children who are learning language. This study will investigate the feasibility of a core vocabulary for preschool children by creating a composite list from the words selected by the caregivers of nonspeaking children. It will investigate how much agreement there is between existing vocabularies in the area of augmentative communication and the vocabularies chosen by parents and clinicians of nonspeaking children. 


\title{
CHAPTER III
}

\author{
METHODS
}

SUBJECTS

Subjects included 15 nonspeaking, nonambulatory children with Cerebral Palsy between the ages of 3.0 and 6.0 years. Nonspeaking was operationally defined as a condition where the child could not use oral speech as his or her primary mode of communication. Nonambulatory referred to a child's inability to use ambulation as the primary mode of mobility. The children were judged by their speech pathologists or teachers to have within-normal hearing and cognitive skills. Since there are no standardized cognitive or language tests for nonspeaking children, reports of informal tests and observations were used for judging cognitive status. No criteria for gender, race, or socioeconomic background was set because of the small population and lack of control for identifying potential subjects across the continent. An informed consent form was approved by the Portland State University Human Subjects Committee.

\section{MATERIALS}

AREV (Advanced Revelations, 1987) data base software by Cosmos, Inc., and an IBM AT computer were used in this study. 


\section{PROCEDURES}

Information and data collection packets were assembled and mailed out to a number of hospitals, schools, and child development centers that specialized in augmentative and alternative communication. The teachers or speech-language pathologists were invited to participate in the study. Each packet included:

1. A cover letter which abstracted the study, described the population and invited clinicians to participate in the study.

2. Description of study and instructions for participation.

3. Two sets of vocabulary 1 ists, one to be filled out by the children's parents and the other to be filled out by either the children's teachers or speech-language pathologists (Appendix Form A).

4. Informed Consent Form to be completed by the children's parents (Appendix Form B).

5. Cover letter and instructions for parents and clinicians (Appendix Form C).

6. Two stamped, self-addressed envelopes.

The cover letter described the study and subject group. The teachers or speech-language pathologists identified possible subjects and discussed the study with the parents. Parents who agreed to participate completed an Informed Consent Form and the vocabulary list. The clinician also completed a vocabulary list. The instructions asked caregivers to list the 110 words that they felt were important to the child's daily communication. The intention was to acquire 100 words for each subject. One-hundred-ten words were listed to ensure there was no duplication of words. The completed vocabulary lists and 
Informed Consent Forms were returned to the investigator. The words were entered into the data base. A set of rules was established to standardize data entry across subjects. They included:

1. Only single words were entered. If more than one word was written on a line, or if the caregiver included different forms of the same word, only the first word as it appeared on the line was entered.

2. Proper nouns, such as names, were marked with the symbol so they could be identified as unique words. Mom, Dad, Grandma and Grandpa were not considered proper nouns.

3. Two words which represented a single concept, such as "ice cream," were hyphenated and entered as one word.

4. Contractions were 1 isted as two separate entries. The rationale was that communication devices do not 1 ist both a root word and negation form. A negative marker is used. For example, "can't" became "can" and "n't."

5. Plurals were 1 isted as the singular form. The plural marker "s" was listed as a separate entry. The rationale was that communication devices do not list both the root and plural form. A plural marker is used.

6. A word was entered once.

7. Synonyms and equivalent forms were entered as a standard form. For example, "yeah," "yep," and "uh huh" were entered as "yes."

8. Child forms were entered as is, and identified with the marker *. For example, "owie" became "*owie."

Confidentiality of subjects was maintained. Each subject was assigned a number and their vocabulary list entered into the data base under this number.

A composite 1 ist was created from the 30 caregiver lists. This list consisted of the words which appeared on three or more of the caregiver lists. The rationale for this was to eliminate words, such as names, which were unique to one child, and at the same time include 
words which were considered important by several caregivers. This composite 1 ist was treated as a separate vocabulary list in the second part of the study.

The second part of the study compared a number of lists which are used as word sources for vocabulary selection for nonspeaking children. Each list was compared to every other list to determine similarity of words. Criteria for selection of the list was either:

1. The presence of that 1 ist on a preprogrammed communication device which is used by children, such as the VOIS 160 .

2. The list had been compiled for symbol sets or sign systems of nonspeaking children, such as the Core Picture Vocabulary.

Four lists meeting one of the criteria were isolated. They were:

Minspeak Starter Vocabulary (Higgins, Shane, Baker, and Coste110, 1986). The Minspeak vocabulary was developed as a software for use with Touchtalker speech output communcation devices. It was designed for use in natural communication by severely physically handicapped individuals. It was based on Teaching English as a Second Language and Basic English (Ogden, 1968) on frequency of word occurrence in spoken English. Three-hundred-ninety-eight words were entered.

VOIS 160 (Phonic Ear, Inc.). This list consisted of single-word vocabulary from the programmed levels of this direct-selection speech output communication device. This is the latest design in the Phonic Ear speech output devices. The rationale for vocabulary selection has not been published. A 1,253 word 1 ist was entered.

Core Picture Vocabulary (Don Johnston, Ltd.). The Core Picture Vocabulary was developed primarily by teachers and speech-language pathologists for use with children. It consists of pictures which can be selected for communication boards. One-hundred-sixty-six words were entered.

Self Talk Communication System (Communication Skill Builders, Inc.). This system was designed as a comprehensive symbol communication system by speech-language pathologist Jan Johnson and a multidisciplinary team 
which included staff from schools, hospitals, sheltered workshops, and nursing homes. Vocabulary is presented in developmental' sequence on a series of communication board overlays. One-hundred-ten-words from Levels 1 and 2 were entered. Leve 1 s 1 and 2 were designed for early and late preschool children.

Respondent Composite List. Although not a published source, the composite list created in the first part of this study served as a vocabulary source. It consisted of 293 words which appeared on 3 or more of the individual caregiver lists.

A total of five lists were used. Each vocabulary list was given a number and entered into the data base as a separate field. Data entry followed the same rules which were established to standardize the caregiver lists.

\section{DATA ANALYSIS}

Descriptive statistics were used in the data analysis. The first research question was investigated by creating a composite list of words selected by the parents of the nonspeaking children. The composite list consisted of every word which was selected by more than two caregivers (appeared on three or more lists). Each individual adult list was then compared to the composite list, and the percentage of the individual 1 ist appearing in the composite was calculated. The mean and standard deviation of percent agreement for vocabularies selected for each child was obtained.

The second research question was investigated through pairwise comparisons of each vocabulary list, a total of ten pairwise comparisons. This yielded the percent of the first list contained within the second list, the percent of the second list contained within the 
first, and a list of the words in common. The common words between lists were calculated as a percent agreement by dividing the number of common words into the total number of words (Beukelman et al., 1984). The third research question was answered by creating one large composite 1 ist from the common words appearing across all five lists. Words on the composite list were listed alphabetically and in descending frequency of occurrence. This allowed for the breakdown of the list into words appearing on five lists, on four lists, on three lists, on two lists and on a single list. 
CHAPTER IV

\section{RESULTS AND DISCUSSION}

This study posed and answered three research questions. The first question sought to determine the similarity of the vocabulary selected by the caregivers of nonspeaking preschool children. The second question looked for the similarity of the vocabulary appearing on different communication aids. The final question looked for the common vocabulary among the communication aid lists and the words generated by the parents and clinicians.

In this chapter, the results of each research question will be presented and discussed.

\section{RESULTS}

The first research question posed was: What were the common words selected by the parents and clinicians of nonspeaking three- to six-year-old Cerebral Palsied children. Thirty 100-word lists were generated by the parents and clinicians of the 15 nonspeaking children. Of the 3,000 words entered into the data base, a total of 781 unique words were generated. The individual lists were combined into one large composite list. Two-hundred-ninety-three words appeared on three or more lists. This list, which will now be 
referred to as the respondent composite list, appears in Appendix D with words listed in descending order of frequency. Since a word was entered only once per subject, the frequency of occurrence refers to the commonality of a word across subjects. For example, a word with a frequency of ten appeared on ten different adult 1 ists.

Each of the 30 individual respondent 1 ists was compared to the 293-word composite list. Similarity between lists was measured by counting how many words on each individual list were also on the composite 1ist. A percentage was calculated for each list comparison. As illustrated in Figure 1 , the agreement between individua 1 ists and the composite list ranged from 65 percent to 89 percent, with a median of 81 percent and a mode of 86 percent. The mean agreement was 79 percent with a standard deviation of 6.9 .

An analysis of the 293-word respondent composite list indicates that no words appeared on a11 301 ists and only 2 words, mom and dad, appeared on 29 lists. In general, more words appeared as commonality across lists decreased. For example, while only 2 different words appeared on 29,28 , and 24 lists respectively, 6 different words (car, eat, hot, no, outside, and yes) appeared on 20 lists and 13 different words appeared on 14 lists. The largest grouping was 69 different words which appeared on 3 lists. This group represented 23.6 percent of the composite list.

The second research question posed was: How similar was the vocabulary appearing on communication aids which were intended for or suitable for use by nonspeaking children. This analysis involved a series of pairwise comparisons between the single-word lists from four 

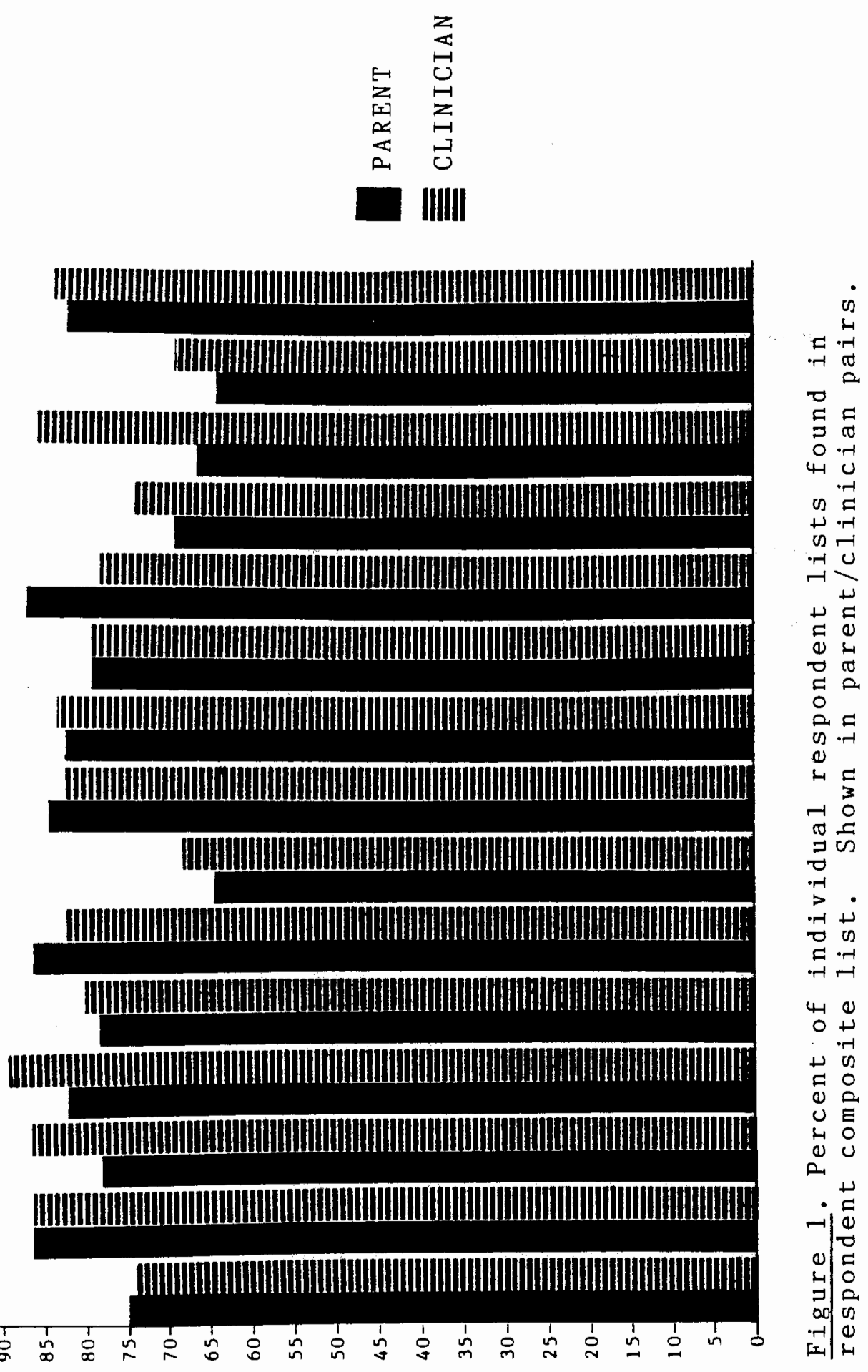
communication devices. These lists were: vocabulary from the Self Talk communication board overlays, Levels 1 and 2 for preschool children; the Core Picture Vocabulary for children; Minspeak starter vocabulary; and vocabulary from the programmed levels of the VOIS 160 speech output device. A fifth list was added which consisted of the 293 words from the respondent composite list created in the first part of this study. The names and size of each list appear in Table I. The data base query yielded two sets of results: the percent of words on the first list contained within the second list and the percent of words in the second list contained within the first. It also provided a list of the words in common between the two lists. The percent agreement between the two lists was calculated by dividing the number of words in common by the total number of words on both lists.

TABLE I

NAME AND SIZE OF COMMUNICATION AID LISTS

Name of List

Respondent Composite List Self Talk List

Core Picture Vocabulary Minspeak Starter Vocabulary VOIS 160 List

\section{Number of Words}

166

398

1,253

The results from the pairwise comparisons are illustrated in Table II and Figure 2. The first two columns of Table II list the percent of each list contained within the other. The third column lists the percent agreement between the two lists. The same information is presented graphically in Figure 2, which shows the number of 
words unique to the first list, the number of words found in both lists and the number of words unique to the second list. The darkened area indicates the common words or overlap between the two lists. The first four comparisons listed in Table II are between the respondent composite list and the four communication aid lists. The percent agreements were: 24 percent with Self Talk, 25 percent with Core Picture Vocabulary, 14 percent with Minspeak, and 17 percent with VOIS 160. It is not surprising that the agreements are higher with the respondent composite list and both Self Talk and the Core Picture Vocabulary since all three lists were developed for children.

\section{TABLE II}

PAIRWISE COMPARISONS BETWEEN COMMUNICATION AID LISTS

Comparison

Respondent Composite to Self Talk

Respondent Composite to Core Picture Vocab

Respondent Composite to Minspeak

Respondent Composite to VOIS 160

Self Talk to Core Picture Vocab

Self Talk to

Minspeak

Self Talk to VOIS 160

Core Picture Vocab

to Minspeak

Core Picture Vocab

to VOIS 160

Minspeak to VOIS 160

Percent of First
List Contained
Within Second
List

32

88

Percent of Second List Contained Within First List
Percent Agreement Between Lists
40

34

93

60

40

93

88

87 
Respondent Composite to Self Talk $197 \| 96] \| 14$

Respondent Composite to Core Picture Vocabulary 176 [1] 1 ind

Respondent Composite to Minspeak

193 InII00]

Respondent Composite to VOIS 160

23 . I.

$49][6] 1$. 105

Self Talk to Core Picture Vocabulary

Self Talk to Minspeak

65 ]|| 45$]$ [1] 353

Self Talk to VOIS 160

\begin{tabular}{|c|c|c|}
\hline \multicolumn{2}{|r|}{10 m. nm } & 1153 \\
\hline
\end{tabular}

Core Picture Vocabulary to Minspeak $115[51][1]-347$

Core Picture Vocabulary to VOIS 160

21 [II]

Minspeak to VOIS 160

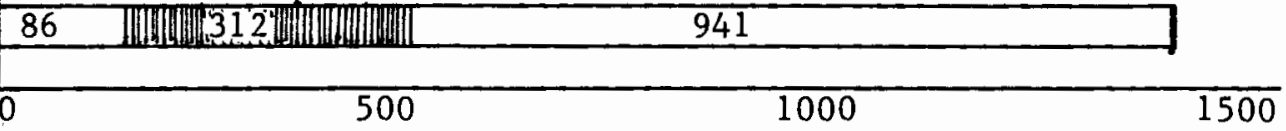

Figure 2. Pairwise comparisons among all communication aid lists. Shaded areas indicate overlap between the two lists.

The next three comparisons on Table II are between the Self Talk list and the other communication aid lists, the Core Picture Vocabulary, Minspeak, and VOIS 160 respectively. There was only a 7 percent agreement with the VOIS 160 list and 9 percent agreement with Minspeak, but a 23 percent agreement with the Core Picture Vocabulary. Again, the two lists developed specifically for children had a much higher agreement. 
The next comparisons listed are between the Core Picture Vocabulary and the Minspeak and VoIs 160 lists. Percent agreement between these lists was also low: 9 percent agreement with Minspeak and 10 percent agreement with the VOIS 160.

The final comparison illustrated in Table II is between Minspeak and VOIS 160 . There was a 19 percent agreement between these lists. Based on the percent agreement figures, the communication aid lists were not similar. While the percent agreements between each list were low, the lists were generally more similar than the percentages suggest. The low percent agreements were largely due to the differences in list sizes; the lists ranged in length from 110 words on the Self Talk list to over 1,200 words on the VOIS 160. Therefore, when looking at the agreement between lists, it is important to consider both the size of the lists and the proportions of the smaller lists which were contained within the larger ones. While percent agreements between lists ranged from 7 to 25 percent, the proportion of the smaller lists found within the larger lists ranged 31 to 93 percent.

The first two columns on Table II show the percent of the first list of the comparison contained within the second and the percent of the second list contained within the first. These figures show that the first three lists (respondent composite list, Self Talk, and Core Picture Vocabulary) are all quite similar. For example, 88 percent of the Self Talk list and 72 percent of the Core Picture Vocabulary were also on the longer respondent composite list. Sixty percent of the words on the Self Talk list were on the Core Picture Vocabulary. 
The Minspeak list was the least similar of all the 1ists. As apparent in Table II, the percent agreements between lists included 9 percent agreement with both the Self Talk list and the Core Picture Vocabulary, a 14 percent agreement with the respondent composite list, and a 19 percent agreement with the VoIS 160 list. In addition, the proportions of the shorter lists within the Minspeak list were low. On $1 y 31$ percent ( 51 words) of the 166-word Core Picture Vocabulary, 34 percent ( 100 words) of the 293-word respondent composite 1ist, and 40 percent ( 45 words) of the 110-word Self Talk list were contained in the 398-word Minspeak list.

Despite the low percent agreements listed in Table II, all of the lists were similar to the 1,253-word vors 160 list. The proportions of each list contained within the vors 160 list included 87 percent of the Minspeak, 88 percent of the Core Picture Vocabulary and 93 percent of both the respondent composite and Self Talk lists. Apparently, the VOIS 160 was large enough and varied enough to encompass most of the vocabulary on other lists.

The third research question posed was: What were the common words from the respondent composite list and the vocabulary on the communication aid lists? To answer this question, the words in common across all five lists were identified. The data base was queried to identify the words which appeared in all of the lists, in four of five lists, three of five lists, two of five lists and in only one list. As apparent in Table III, the majority of words appeared on only one 1ist. Of a total of 2,219 words across the 5 lists, 1,336 words were unique. Only 30 words or 2 percent of the list, were on all five 
1ists. These words are listed in Table IV (p. 47). Fifty-six words were on 4 lists and 117 words were on 3 lists. Eight-hundred-eleven words (60 percent of the list) appeared on on ly one of the five lists.

\section{TABLE III}

NUMBER OF WORDS IN EACH COMMONALITY GROUPING FROM COMPARISON OF FIVE LISTS

Commona lity Grouping 5
Number of Words in Grouping

116

342

811

\section{DISCUSSION}

In general, this research found that while a similar population of nonspeakers had similar vocabulary needs, the published 1 ists which were available for lexicon selection differed in size and content. The results of this study reflect the results of previous studies in the area of vocabulary use and lexicon selection for augmentative and alternative communication.

The first research question looked for the common words selected by the caregivers of the 15 preschool children and created a 293-word composite list from the words which appeared on 3 or more lists ( 10 percent of the lists). The rationale for including only those words which appeared on three or more lists was to eliminate words such as proper names which might have appeared on both parent and clinician lists, but at the same time produce a varied and robust composite. A 1ist of 200 to 500 words was the ideal size (Beukelman et a1., 1984; 
Beukelman et al., 1989). While a commonality cutoff of three had the potential to produce an extremely large list, earlier research on vocabulary selection indicated low agreement between nonspeakers' lexicons (Karlan and Lloyd, 1983; Yorston et al., 1988). For example, when Karlan and Lloyd created a composite list of words generated by the caregivers of severely handicapped adolescents, they found that only 242 words were selected by 10 percent or more of the respondents. In this study, the commonality cutoff of 10 percent produced a composite list of similar size.

Comparisons between individual lists and the 293-word respondent composite list showed that from 65 to 89 percent of the individual lists were present on the composite, with a mean agreement of 79 percent. The high agreement between the individual adult lists and the composite list indicates that adults consider similar words important for communication. At least 65 , and as many as 89 , of the 100 words selected by the caregivers were important to other caregivers. This confirms that the creation of a core vocabulary for preschool children is feasible. These results reflect the results of studies on the vocabulary use of adult populations which found that diverse groups of nonspeaking adults used very similar vocabularies (Beukelman et al., 1984; Yorkston et a1., 1988). For example, the research by Beukelman which analyzed the word usage of a group of nonspeaking adults found that an average of 80 percent of each individual's communication needs could be met by a 500-word composite list. Yorkston and her colleagues (Yorkston et al., 1988) found that an average of 70 percent of the adult nonspeakers' lexicons were met by a 744-word composite 1ist. 
The results of the present study are even more encouraging when one considers that the adults were asked merely to 1 ist the words which they felt were important for the child to communicate and were listing words for a number of environments. Certainly if the adults had been asked to 1 ist words for a specific rather than a daily environment there would have been higher agreement in the words selected. However, the inclusion of words for different situations cannot be considered a drawback. All of us have different lexicons for different situations and if nonspeaking children are to communicate effectively in all environments, they must have access to a variety of words.

Further to this, the composite list was generated by a diverse group of adults. The composite list contained words selected by parents, teachers and speech-language pathologists. These caregivers saw the children in different situations and probably chose words which facilitated communication in those environments. Comparisons between each parent-clinician pair showed that from 26 to 51 of the words on the 100-word lists were the same. There was a mean agreement of 37 percent which suggests that while there was some overlap between lists, the parents and clinicians chose different words. One can suspect that the parents would list more home-related words and the teachers and speech-language pathologists more school- or clinicrelated words, because these were the contexts in which they interacted with the children. A cursory comparison of the words selected by parents and the words selected by clinicians showed that in fact the parents did generate more daily care and food words (bath, sleepy, 
peanut-butter, cerea 1 ) and the clinicians generated more activity words (computer, crayon, glue, puzzle). This is not a surprising result: adults can be expected to choose the words which the child would use most in the time they spent with the child. The tendency for different caregivers to select unique and different words is why many clinicians suggest that a variety of people should be included in the vocabulary selection process (Carlson, 1981; Lowe, 1988). When Lowe compared the words generated by parents, teachers, and clinicians she also found that each group added unique words. It must be noted, however, that the words which were chosen frequently were chosen by both parents and clinicians. In comparing the words selected by parents to the words selected by clinicians on the respondent composite list, there was over 50 percent agreement between the 1 ists. The words in common were both home and school related. This is another indication that the vocabulary chosen by the adults was fairly similar and supports the development and use of a core vocabulary. Despite the high agreement between individual 1 ists and the respondent composite 1ist, the majority of words were used by a small percentage of the adults. The adult-generated vocabularies yielded a total of 781 unique words across all lists. Over half of these words appeared on one or two lists and were not included in the composite list. While this does not contraindicate the creation of a core vocabulary, it does reinforce the fact that vocabularies for nonspeakers require a certain amount of individualization. There will always be some words, often referred to in the AAC literature as "fringe" vocabulary, which are unique to one individual. Each adult 
listed from 11 to 35 unique or "fringe" words on their 100-word lists. These fringe words included names of family members, friends and teachers; television shows; and specific foods and activities. This result was not unexpected and reflected the results of a case study reported by Yorkston, Honsinger, Dowden, and Marriner (1989). A comparison of a nonspeaking woman's lexicon to the vocabulary on a number of published lists indicated that no one published list could completely meet the woman's vocabulary needs. In this instance, the authors suggested that a combination of vocabulary selection methods was required to ensure selection of an adequate vocabulary. Certainly a core vocabulary is not intended to be the only vocabulary source for a nonspeaking individual but a too 1 to increase the efficiency and effectiveness of the vocabulary selection process. It can serve as a framework for word selection thereby allowing caregivers to choose the words which are important to the individual child. While Blau (1983) supported the use of core vocabularies in her functionally based nesting mode1, her prime consideration for word selection was the functional utility of each word. The lexicon had to include words which were important to the nonspeaker and his or her caregivers and reflect events in the individual's life. In other words, while Blau felt a core vocabulary could meet the developmental requirements of the initial lexicon, the lexicon should also contain a number of unique words.

Although 293 words appeared on the respondent composite list, there were very few words selected by the majority of the respondents. Most of the words on the respondent composite were selected by only 
three or four individuals. This suggests that, other than a few high frequency or high utility words, the adults chose fairly diverse vocabulary. As a general rule in looking at composite lists, the more times a word appears across individual lists, the greater its importance or utility. Certainly the words which had high commonality (mom, dad, go, drink, play, happy, home, help) are very important for communication. At the same time, the words which appeared on only a few 1 ists were also potentially useful to nonspeaking children. Words such as ice-cream, footba11, funny, name, okay, see, silly, away, block, candy, cow, hate, movie, and yummy are among the words which appeared on three or four lists. Since these words are not specific to one child and cover a variety of foods, actions, activities, and feelings, they may be important to include in a core vocabulary. Further, while these words appeared with low frequency in this study, if the sample had been larger, or if the adults had been allowed to list more words, these words may have appeared with higher frequency. When discussing the suitability of the respondent composite list, it is also important to discuss its contents or composition. An objection that some clinicians have to parent-generated lists is the tendency for such lists to be needs related (Car1son, 1981; Lowe, 1988). Lists chosen by parents often have the words the parents need or want their children to express rather than what the children may want to say. The earlier comparison of the parent-and clinicianselected vocabulary did indicate that while the parents chose many words related to basic needs, they also chose many other words. The words on the composite list were generated by both parents and 
clinicians and covered a variety of communication needs. A preliminary analysis of the content of the composite list indicated that, in addition to words that communicated basic needs (eat, drink, hungry, potty, hurt), the list included words of feelings (angry, scared, silly); action words (go, come, play); pronouns (I, you); descriptors (hot, angry, big, little); negation (no); a variety of objects (toy, dog, puzzle, car, crayon); and foods (juice, apple, peanut-butter, banana). Therefore, the adults were sensitive of their children's need to express a variety of things. In addition to communicating their basic needs, the vocabulary on the composite list would allow the children to label objects, make social comments, express their feelings, and request or reject a variety of objects or activities. Many clinicians suggest that the initial lexicon include developmentally appropriate words: words that speaking children of the same developmental level might want to use (Carlson, 1981). A cursory comparison of the respondent composite list to lexicons developed for speaking but language delayed preschool children revealed many similarities. For example, the composite list contained at least one word from every semantic category suggested for initial lexicons by Lahey and Bloom (1978). This included words for expressing rejection and nonexistence (no); cessation (stop, al1-done); recurrence (more, again); existence (that); actions (make, drink, do); locatives (under, over, outside); and attributes (big, little, blue). In addition, the respondent composite list contained 25 of the 35 items suggested for initial lexicons by Holland (1975). It must be noted that six of the items recommended by Holland were to be chosen specifically for each 
child. The names of family and friends and specific foods or activities are generally considered fringe vocabulary, and as such would not be included in a core vocabulary. When this is accounted for, the composite 1 ist contained 25 of 29 ( 86 percent) of the genera 1 words suggested by Holland. The words in common with Holland's lexicon included : kiss, hate, scared, more, go, up, down, bal1, block, and car. These words would allow nonspeaking children to communicate a number of feelings, requests and commands. In addition to this, a comparison of the adult composite list to a developmenta11y based initial sign lexicon indicated that 45 of the 50 items suggested by Fristoe and Lloyd (1980) appeared in the respondent composite list. Again, the common items (no, more, drink, eat, play, big, open, apple, ball, IV, table) would allow nonspeaking children to express a variety of needs and wants.

Further support for the developmental appropriateness of the respondent composite 1 ist is that 102 of the words on the composite list appear on a 1 ist of 250 frequently used words of speaking, preschool children (Beukelman et a1., 1989). Thirty-five percent of the words selected by adults for their nonspeaking children were actually used by speaking children of the same age. Examples of words used frequently by all of the speaking children and also selected by adults include: I, is, you, this, my, here, and, no, one, do, want, in, on, have, can, what, get, go, me, need. It is important to note that the study by Beukelman and his colleagues looked at the types and frequency of the words used by speaking preschool children in order to develop a core vocabulary for nonspeaking children. The results 
showed that the words which were used most frequently by the children tended to be "structure" words, words which provided the framework of an utterance rather than the content. Basing a core vocabulary solely on the words used by speaking children would result in a lexicon of many structure words. While Yorkston (1988) stressed that structure words should form a major part of a core vocabulary, nonspeaking children must also have access to low-frequency but high-utility content words. The appearance of the same structure words on both the respondent and speaking children's composite lists suggests that the composite lists provide a developmentally appropriate framework for conversation as well as more specific content words. It is also important to note that the vocabulary for the speaking children was collected in a classroom setting in an attempt to contribute to the development of an academic core vocabulary. Since the speaking children were taped throughout the school day, one would expect their vocabulary to be school related. Given the fact that the respondent composite list contained daily vocabulary with words for both home and school, a 35 percent agreement between the lists is quite high. Certainly there is a close enough agreement between the two lists to say that the words on the composite list reflect the vocabulary of normally developing preschool children in at least one setting. This and the previous informal comparisons suggest that although the study did not specifically address developmental issues, the composite list contained many developmentally appropriate words. It may be that the 
parents and clinicians of preschool children are in tune to the developmental levels of their children and are adept at choosing appropriate words.

The second research question indirectly addressed the functional appropriateness of different communication aid 1 ists which are used for preschool children. This was similar to the question posed in earlier research by Yorkston and her colleagues which compared a number of published vocabulary lists to assess the suitability of each list for vocabulary selection for nonspeaking adults (Yorkston et al., 1988). The present study looked at the same issue but focused on the vocabulary needs of preschool children. It was based on the premise that while a number of lists serve as vocabulary sources for nonspeaking children they may not adequately meet the vocabulary needs determined by the caregivers. As reported in the results section, the percent agreement between different lists was generally low. There was closer agreement in both size and content among the three 1 ists developed specifically for children (respondent composite list, Self Talk list, and Core Picture Vocabulary). These findings are somewhat different than those of earlier research which reported that published lists varied greatly in both size and content (Yorkston et al., 1988). The results of the comparisons with the Minspeak list are of interest because the percent agreement between the Minspeak vocabulary and the other lists was consistently low. Since the words in the Minspeak vocabulary were chosen on the basis of frequency of occurrence of spoken English, these results support the premise that 
vocabularies based solely on frequency of occurrence do not accurately reflect the needs of nonspeakers (Yorkston et al., 1988). The low agreement between Minspeak and the three child-specific lists forces one to question the utility and validity of Minspeak vocabulary for use with preschool children.

As discussed in the results section, the low percent agreement between lists was largely due to the range of list sizes. The pairwise comparisons showed that large parts of the smaller lists were actually contained within the larger 1ists. For example, 88 percent of the Self Talk list was contained on the respondent composite list, and 93 percent of the respondent composite list was contained within the VOIS 160 list. In fact, the VOIS 160 list contained a large proportion of all of the smaller lists. This indicated that the Vors 160 lexicon was extremely comprehensive and as such is a valuable source for vocabulary selection. If clinicians were able to review only one vocabulary list, they could be sure that the VoIs 160 contained many of the words also present on other lists.

At the same time, clinicians must consider that even though large parts of the smaller lists appeared on the longer lists, none of the smaller lists were completely accounted for by the larger lists. This reinforces the earlier discussion on the need for some individualization of a nonspeaker's lexicon. It also must be stressed that the larger lists have limited utility for the preliterate child. As pointed out by Yorkston, Honsinger, Dowden, and Marriner (1989), the more words a list contains, the more words there are that are irrelevant to the user. This is an especially important consideration for 
an initial lexicon which is generally small in size. This means that even if much of the needed vocabulary is present on the 1 ist, the clinicians and parents must still go through the list and determine which of the many words are important for a preschool child.

The final research question, which looked for the overlap of words between all of the lists, served to eliminate those words which appeared on only one $1 \mathrm{ist}$. This analysis was useful because it indicated similarities which did show up in the pairwise comparisons. One could expect to find the most important or useful words in all or most of the lists. These words might be a good beginning for a core vocabulary. This comparison organized words by frequency of occurrence. It showed that of a total of 2,219 words across the 5 lists, 1,335 words were unique. Only 2 percent of the words, however, were found on all of the lists. Sixty percent ( 811 ) of these words appeared on only 1 list. Since the majority of word's appeared on only one list, it is obvious that the lists were not similar. In part, this is a reflection of the range of list sizes. When there is a difference of over 1,100 words between the smallest and the largest 1 ists, one can expect many words to appear on $1 y$ on the largest 1 ist.

In general, when determining the relative importance or utility of individual words, the utility of a word increases with increasing agreement across vocabularies. A cursory look at the core of 30 words which appeared on al1 5 lists (Table IV) indicated that it contained words important to all children. These included words to express basic needs (eat, drink, help); requests (more, stop, open, down); attributes (big, cold); action words (go, play); locations (under, 
down); feelings (happy, sad); and labels (shirt, shoe, dog, TV). Indeed this may be a reasonable beginning in the creation of a core vocabulary for nonspeaking, preschool children.

\section{TABLE IV}

WORDS WHICH APPEARED ON ALL FIVE COMMUNICATION AID LISTS

$\begin{array}{llll}\text { big } & \text { get } & \text { more } & \text { shirt } \\ \text { cold } & \text { go } & \text { no } & \text { shoe } \\ \text { come } & \text { happy } & \text { off } & \text { stop } \\ \text { dog } & \text { he 1p } & \text { open } & \text { TV } \\ \text { down } & \text { I } & \text { out } & \text { under } \\ \text { drink } & \text { in } & \text { play } & \text { want } \\ \text { eat } & \text { know } & \text { sad } & \text { wash } \\ & & & \text { wheelchair }\end{array}$

While it is tempting to label the words which appeared on four or five lists as important and dismiss the words which appeared on only one 1 ist, this is not a realistic approach to the creation of a core vocabulary. Of the 811 words which appeared on 1 list, one would expect to find words of varying importance for preschool children. While the words beer and government have limited utility for preschool children, teddy-bear and hotdog may be very important. Because the communication aid lists were developed for different purposes, deve1oping a core vocabulary simply from a cutoff in word commonality is invalid. It is impossible to determine word importance simply from commonality across the different lists. For example, while the word al1-gone appeared on only two lists, most clinicians and language specialists view it as a very important word for young children. This is supported by its inclusion on the initial lexicons developed by Ho11and (1975), Lahey and B1oom (1978), and Fristoe and Lloyd (1980). 
Realistically, this word is as important for children's communication as more general labels such as telephone and table which appeared on four lists. Obviously, a core vocabulary based on the common words across communication aid lists is no better than the similarity of the 1ists. The data in this study indicate that the lists available on communication aids are not similar; therefore, a composite list based on word commonality will be limited in size and contain general rather than child-specific words. This type of list will not encourage cognitive growth or language development and is not suitable for the critical initial lexicon.

In sumary, when faced with the difficult task of selecting vocabulary for the initial lexicon, parents and clinicians must decide whether to generate a unique vocabulary for the child or depend on one of the many available lists. This literature suggests that vocabulary selection is a difficult and time-consuming process. Many caregivers are unable to create their own lexicons and must depend on published lists, yet this study indicates that the lists on communication aids differ in both size and content. Which lists do the caregivers choose? The results of the pairwise comparisons indicate that the Minspeak vocabulary does not meet the vocabulary needs of preschool children. While the VOIS 160 list contains many useful words, it is too large to save the parents and clinicians much time or effort. The 293-word respondent composite 1 ist may be the best alternative. While the sample size was relatively small and the caregivers a diverse population, the fact remains that the list was developed specifically for preschool children and reflects a large proportion of their 
vocabulary needs. It contains words which are developmentally appropriate as well as words which have high utility to nonspeakers. While there is no empirical data to attest to its usefulness in the vocabulary selection process or the validity of the words it contains, it is a new alternative for adults involved in lexical selection. The development of a core vocabulary for nonspeaking, preschool children must be a priority in the field of augmentative and alternative communication. This study and the respondent composite list may be a good starting place for this task. 
CHAPTER V

SUMMARY AND IMPLICATIONS

\section{SUMMARY}

The selection of the initial lexicon is one of the most important decisions made in the implementation of augmentative communication systems with preliterate, nonspeaking preschool children. If a communication aid is to be adopted by a child, the words available on the device must be interesting to the child and encourage communication. The vocabulary must allow for cognitive growth and foster language development. Ideally, a lexicon would be customized for each nonspeaking child's particular interests, vocabulary needs and deve1opmental level. The reality is that vocabulary selection is a difficult and time-consuming process. Parents and clinicians do not always have the time or expertise to develop an individualized lexicon and must depend on a prepared list. These lists are not always appropriate for preschool children. A carefully developed core vocabulary could serve as a framework for the initial lexicon and would ensure that the words available to the children promoted communication and language growth. This would allow caregivers to concentrate on the smaller, individualized portion of the lexicon.

The purpose of this study was to compare the words generated by the caregivers of nonspeaking, preschool children to words present in 
the lexicons of communication aids suitable for these children. It sought to determine the feasibility of a core vocabulary for this population and if lists on communication aids met this need. The subjects were 15 nonspeaking, nonambulatory children with Cerebral Palsy between the ages of 3.0 and 6.0 years. The children were reported to have within-normal hearing and cognitive skills. The parents and clinicians were asked to list the 100 words that they felt were most important for their child to communicate in his or her daily environment. One large composite list was created from the 30 individual lists. A 1 ist of 293 words was created from words which appeared on 3 or more adult lists. Each individual list was compared to this composite list and the number of common words from the individual 1 ists and the composite list were counted. Similarity was calculated as a percent. The agreement between individual 1 ists and the composite list ranged from 65 to 89 percent, with a mean of 79 percent. These results indicate that the parents and clinicians of nonspeaking children chose similar vocabulary and suggests that the development of a core vocabulary is indeed possible.

The respondent composite list was then compared to the lists from communication aids which were intended or suitable for use with preschool children. These published lists were: vocabulary from the Self Talk communication board overlays, Levels 1 and 2; Core Picture Vocabulary; Minspeak starter vocabulary; and vocabulary from the programmed levels of the VOIS 160 speech output device. The data base was queried to perform a series of pairwise comparisons between lists. This query provided three figures: the percentage of the words 
from the first list which appeared in the second 1 ist, the percentage of words from the second list which appeared in the first list, and the number of common words between the two lists. A percent agreement between each set of lists was calculated by dividing the number of common words into the number of words on both lists.

The results of this set of comparisons indicated that the percent agreement between 1 ist pairs ranged from 7 to 25 percent. This low overa11 agreement was, in part, the result of the differences in list sizes, which ranged from 110 words on the Self Talk 1 ist to 1,253 words on the VOIS 160 list. A closer analysis of the pairwise comparisons showed that large proportions of the smaller lists were actually present in the larger lists. For example, while the percent agreement between the Self $\mathrm{Talk}$ and respondent composite list was only 24 percent, 88 percent of the 110-word Self Talk list was contained within the 293-word respondent composite list. With the exception of the Minspeak list, which was not similar to any of the smaller lists, a larger proportion of the smaller lists were contained in the larger 1ists. It is important to note that none of the smaller lists was completely contained within the larger lists.

In the final comparison, one composite list was created from the 2,219 words appearing across al1 5 lists. Of a 1ist of 1,336 unique words, a core of 30 words appeared on all of the lists. Eighthundred-eleven words appeared on $1 y$ once across a11 five 1 ists.

The high agreement between words selected by the caregivers of nonspeaking preschool children indicates that the use of a core vocabulary is indeed feasible. A comparison between the respondent 
composite list and the lists currently available on communication aids for use with nonspeaking children indicates that the lists differ in size and content. No list completely meets the vocabulary needs as determined by the adults or can be considered suitable as a core vocabulary. Both the 293-word respondent composite list and the core of 30 words which occurred across all 5 communication aid lists may be useful in the development of a core vocabulary for nonspeaking, preschoo1 children.

\section{IMPLICATIONS}

\section{Clinical Implications}

The issue of customized versus core vocabularies is one which is very important in vocabulary selection. The need for the initial lexicon to include words which are interesting and important is something which is stressed by both researchers and clinicians. Studies which compared individual nonspeakers' lexicons to published lists found that no published or prepared list, regardless of size, completely meets individual vocabulary needs (Yorkston et al., 1988; Yorkston et a1., 1989). In the present research one cannot ignore the fact that over half the words generated by parents and clinicians appeared on only one 1 ist. This reflects and reinforces the results of the earlier research which found that core vocabularies should serve as one of several vocabulary sources. Clinically this reinforces the need for parents and clinicians to review the vocabulary on their children's communication aids and add words which are specific to their child. 
The high agreement between individual respondent lists and the composite of the respondent lists showed that the respondent composite list contained many of the words the caregivers considered important for their children to communicate. In other words, the children "used" similar words. These results support the clinicial use of a carefully developed core vocabulary with the preschool population. The pairwise comparison between lists from different communication aids indicates that currently available lists differ in length and in composition. Despite the fact that the use of a core vocabulary is feasible for nonspeaking children, none of these lists are really suitable as a core vocabulary or the sole vocabulary source. Clinically, this suggests that clinicians should look carefully and critically at the words available on whatever communication aid is selected for the clients. If the words are not appropriate, the parents and clinicians may be required to either create their own lists or review multiple lists when choosing words for their children. The communication aid lexicon could be viewed as one of several vocabulary sources. This is not, however, a realistic alternative. The literature indicates that parents and teachers find lexicon selection both difficult and time consuming (Lowe, 1988). If the adults choosing the vocabulary are not trained in vocabulary selection, do not understand the need to include motivating and developmentally appropriate words, or do not have time to select words, then the vocabulary may not encourage the children to communicate. In these cases, even a less-than-perfect preprogrammed vocabulary will be better than a poorly selected or hastily chosen lexicon. At best, a preprogrammed 
vocabulary will ensure that the child has access to at least some motivating and developmentally appropriate words. If the caregivers must depend on only one prepared list, the respondent composite list created in this study may be a more reasonable source than the ones available in the field.

Another important clinicial implication is the low agreement between the Minspeak vocabulary and the other communication aid lists. It seems apparent that the words available on the Minspeak vocabulary are not suitable as a core vocabulary and may not be suitable for use with preschool children. This is not a major problem in vocabulary selection for communication boards or other communication aids which allow the parent or clinician to select vocabulary on a word-by-word basis. However, the Minspeak vocabulary is preprogrammed into the software for the Touchtalker speech output devices, devices which are used frequently with children. In this situation, the parents and clinicians must review both the words needed by the child and the words available on the device and, if necessary, reprogram the device with more suitable vocabulary.

\section{Research Implications}

There are several important implications for future research. While a core vocabulary for preliterate children has not yet been developed, the agreement between individual respondent lists and the respondent composite list support its creation. The pairwise comparisons between the device lists and the respondent composite list suggest, however, that the lists which are currently in use are not 
particularly similar and are not suitable as core vocabularies. Although these lists are not suitable for core lexicons, their use in the field indicates that clinicians have a need for some sort of prepared lexicons. Since most clinicians do not have the time or training to select lexicons for each child, the creation of a core vocabulary must be a research priority. While this study did not attempt to create a core vocabulary, the composite list generated from the individual respondent 1 ists could serve as a basis for development of a core. There are several areas which were not specifically addressed in this study which must be considered in the development of a core vocabulary.

The first consideration is the need to include developmentally appropriate words. One issue that is stressed in the selection of an initial lexicon is the need to include words which foster language development and cognitive growth. This means the lexicon must include words that speaking children of comparable developmental stages use. While the respondent composite list contained many of the words recommended for initial lexicons for language intervention with language delayed children, a more formal lexical analysis is necessary to determine content. Yorkston and her colleagues recommended that a core list contain a high proportion of structure words to act as a framework for communication (Yorkston et al., 1988). A lexical analysis could also determine what proportion of structure versus content words provides for the most flexibility of communication.

To ensure that a core vocabulary is truly developmentally appropriate, the words actually used by speaking children must be 
collected and analyzed. Words which are used frequently by speaking children may be important to include in a core vocabulary. In fact, this type of research is currently being conducted by researchers such as David Beukelman at the University of Nebraska and Melanie Fried-Oken at the Rehabilitation Institute of Oregon. Another ongoing research project by Fried-Oken is the collection and analysis of the vocabulary used by speaking, nonambulatory children. It has been suggested that reduced mobility affects both the language acquisition and lexical choices of nonambulatory children. The words generated by physica11y handicapped children may closely reflect the vocabulary needs of their nonspeaking peers.

A second consideration for research is the need to include environmentally specific words. The respondent composite list created in this study contained words selected by both parents and clinicians, so the words were appropriate for daily environments. To foster language develoment in particular settings, however, children must have the appropriate words available to them. For example, to succeed in school, children need "schoo1-type" words. To allow for this, researchers must look for words from specific settings and activities as we 11 as the more general "daily" words. In other words, the deve1opment of separate and specific core vocabularies should be a priority.

While the composition of the initial lexicon has received considerable discussion, its optimal length has yet to be addressed in research. Initial lexicons can range in length from two or three words to several hundred. Fristoe and Lloyd (1980) chose a 50-word 
sign lexicon based on children's tendency to put 2 words together when they have this size of vocabulary, but there is no evidence that this is the best size. Essentially, a core vocabulary must be large enough to account for a large proportion of a nonspeaker's lexicon without including a large number of unnecessary words. At a certain point, increasing the size of the list does not produce a significantly higher agreement. The 293-word composite list created from words which appeared on 3 or more respondent lists accounted for 65 to 89 percent of the words on each individual list. While this list is of sufficient size to account for a large part of the vocabulary appearing on each list, it is not conclusive that this is the ideal size. Research on nonspeaking adults, for example, found that a 500 -word composite list could cover 80 percent of individual adults' vocabulary needs (Beukelman et al., 1984). A composite list of 250 words was sufficient to meet 85 percent of the vocabulary needs of speaking preschool children (Beukelman et al., 1989). These results suggest that an effective core vocabulary should be somewhere between 200 and 500 words. Research must determine the size which will best meet children's vocabulary needs and at the same time be a reasonable size for clinicians to review or teach. This may require that software be programed to determine both the frequency of use of different words for individual users and the commonality of use across a number of individuals. While such a software is in design at the University of Nebraska, it may be many years before it is available for clinicial use. 
A final area for consideration in research is determining whether the words available on core vocabularies are truly important for nonspeaking children. This can only be determined by a process of social validation. Social validation can take two forms. The caregivers of the children or the children themselves can rate the importance of the words presented on the core list. The parents and clinicians know their children's favorite foods, activities and routines. They are aware of their children's vocabulary needs in a number of settings. Although generating words for the initial lexicon is difficult, rating the words is a significantly faster and easier process and would help to ensure that the words included on a core were truly important. A second method of social validation would involve recording the frequency and commonality of use of different words on a core vocabulary. The adults, or in some cases an electronic data collector in a communication device, would be required to record the words actually used by a number of nonspeaking children for an extended period of time and over a variety of situations. Obviously, this will be a difficult process but one which is necessary to determine which words allow and encourage communication and therefore truly belong on a core vocabulary. 


\section{REFE RENCES}

Bates, E. (1976). Language and Content, New York: Academic Press.

Beuke 1man, D., Jones, R., and Rowan, M. (1989). "Frequency of Word Usage by Nondisabled Peers in Integrated Classrooms," Augmentative and Alternative Communication, 5, 243-248.

Beuke lman, D., Yorkston, K., Poblete, M., and Naranjo, C. (1984). "Frequency of Word Occurrence in Communication Samples Produced By Adult Communication Aid Users," Journal of Speech and Hearing Disorders, $49,360-367$.

Blake-Huer, M. (1984). "Comparing Receptive and Expressive Language Ski1l Development of Nonspeakers and Speakers," Third International Conference on Augmentative and Alternative Communication, Cambridge.

Blau, A. (1983). "Vocabulary Selection in Augmentative Communication, Where Do We Begin?" In H. Winitz (ed.), Treating Language Disorders: For Clinicians by Clinicians, Baltimore: University Park Press, 205-234.

Carlson, F. (1981). "A Format for Selecting Vocabulary for the Nonspeaking Child," Language, Speech and Hearing in the Schools, $12,240-245$.

Communication Skil1 Builders, Inc. Self Ta1k Communication Systems.

Don Johnston, Ltd. Core Picture Vocabulary.

Fristoe, M., and Lloyd, L. (1980). "Planning an Initial Expressive Sign Lexicon for Persons with Severe Communication Impairment," Journa 1 of Speech and Hearing Disorders, 45, 170-180.

Harris, D., and Vanderheiden, G. (1980). "Enhancing the Development of Communicative Interaction." In R. Schiefelbusch (ed.), Nonspeech Language and Communication, Baltimore: University Park Press.

Higgins, J., Shane, H., Baker, B., and Coste11o, J. (1986). "Systematic Approaches to Vocabulary Selection for Communication Aid Users." A short course presented at the Annual Convention of the American Speech Language and Hearing Association, Detroit, Michigan. 
Holland, A. (1975). "Language Therapy for Children: Some Thoughts on Context and Content," Journal of Speech and Hearing Disorders, $40,514-523$.

Karlan, G., and Lloyd, L. (1983). "Considerations in the Planning of Communication Intervention: Selecting a Lexicon," The Journal of the Association for the Severely Handicapped, $8,13 \overline{-25}$.

Lahey, M., and Bloom, L. (177). "Planning a First Lexicon: Which Words to Teach First," Journal of Speech and Hearing Disorders, $42,340-349$.

Lowe, D. (1988). "Vocabulary Selection for Augmentative Communication: A Comparison of Three Techniques," Augmentative and Alternative Communication, in press.

Meyers, L., Andersen, C., and Liddicoat, C. (1984). "Perceived Communication Needs of Developmentally Delayed Nonspeaking Children," The Psychological Record, 34, 55-68.

Nelson, K. (1973). "Structure and Strategy in Learning to Talk," Monographs for the Society for Research in Child Development, 38 .

Ogden, C. (1968). Basic English: International Second Language, New York: Harcourt Brace and Wor 1 d.

Owens, R. (1988). Language Develoment: An Introduction, 2nd ed., Columbus: Merrill Publishing Company.

Phonic Ear, Inc. VOIS 160.

Porter, P. (1987). "Augmentative Communication: Selection of an Initial Vocabulary," Physical and Occupational Therapy in Pediatrics, 7, 79-90.

Reichle, J., Williams, W., and Ryan, S. (1981). "Selecting Signs for the Formulation of an Augmentative Communicative Modality," The Journal of the Association of the Severely Hand icapped, $6, \overline{48-56}$.

Rescorla, L. (1989). "The Language Development Survey: A Screening Tool for Delayed Language in Toddlers," Journal of Speech and Hearing Disorders, 54, 587-599.

Reznick, J., and Goldsmith, L. (1989). "A Multiple Form Word Production Checklist to Assess Early Language," Journal of Child Language, $16,565-582$.

Vanderheiden, G., and Lloyd, L. (1986). "Communication Systems and Their Components." In S. Blackstone (ed.), Augmentative Communication: An Introduction, Maryland: American Speech-Language Hearing Association, 49-61. 
Vanderheiden, G., and Yoder, D. (1986). "Overview." In S. Blackstone (ed.), Augmentative Communication: An Introduction, Maryland: American Speech-Language Hearing Association, 1-28.

Wilson, K. (1980). "Selection of a Core Lexicon for Use with Graphic Communication Systems," Journal of Childhood Communication Disorders, 4, 111-123.

Yorkston, K., Dowden, P., Honsinger, M., Marriner, N., and Smith, K. (1988). "A Comparison of Standard and User Vocabulary Lists," Augmentative and Alternative Communication, 4, 189-203.

Yorkston, K., Honsinger, M., Dowden, P., and Marriner, N. (1989). "Vocabulary Selection: A Case Report," Augmentative and Alternative Communication, 5, 101-108. 
APPENDIX A

VOCABULARY FORMS TO BE COMPLETED BY PARENTS AND CLINICIANS 


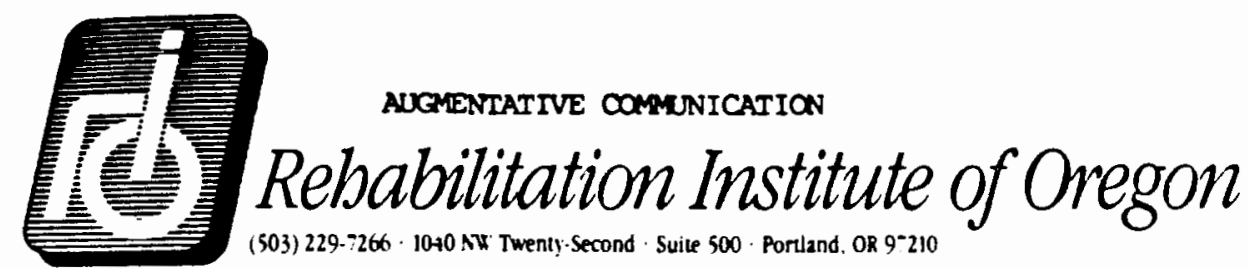

Oufpattent Program

Dear Parent:

Please fill out the following infomation about your child.

Child's initials:

Birthdate:

Sex:

Number of children in family:

How many siblings are older than the preschooler?

How many siblings are younger than the preschooler?

How many hours each day do you spend with your child?

What is your relationship to the child?

What is your child's main methods of cammunication?

What form(s) of augmentative cammunication has your child used in the past?

Have you and/or your child's therapists/teachers prepared a vocabulary list already?

If yes, how many words and/or phrases are included in the list?

Please list the 110 most important words your child needs in order to communicate effectively during a regular day. Some parents find it easy to thinks of this list as the 110 words that their child would use a lot if he/she could talk. Before completing the list, you may find it helpful to observe your child carefully for a while. If a vocabulary list has already been made for your child, you may use the words in that list. Please put a next to those words that were previously chosen.

Below is a form with blanks for your 110 words. Please put a check in the column called "Essential hords" if the word is one that must be included for daily communication. Put a check in the column called "Extra hords" if the word would be nice to include, but is not essential for daily communication. Different forms of the same root word (think, thought, thinking) can be listed as separate words. 


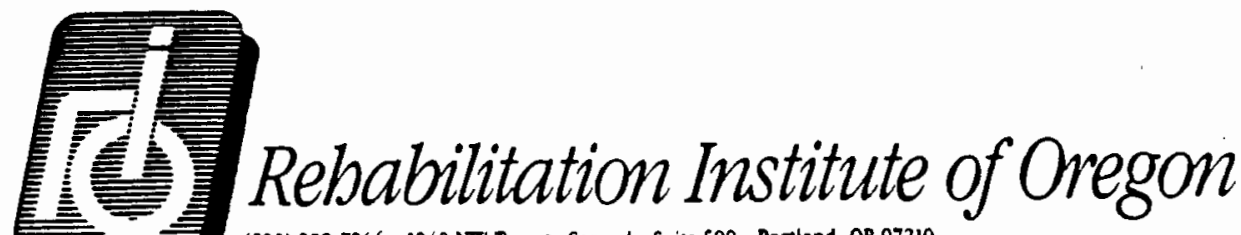

(503) $2297266 \cdot 1040 \mathrm{NW}$ Twenty-Second - Suile $500 \cdot$ Porsand, OR 97210

Ouppatien: Program

Dear Speech-Language Pathologist or Educator:

Please fill out the following information about your client.

Child's initials:

Birthdate:

Sex:

What is your relationship to child?

What is the child's main methods of communication?

What form(s) of augmentative communication has your client used in the past?

Have you and your client's parents prepared a vocabulary list in the past?

If yes, how many words and/or phrases are included in the list?

Please list the 110 most important words your client needs in order to communicate effectively during a regular day. Some clinicians find it easy to think of this list as the 110 words that their client would use a lot if he/she could talk. If a vocabulary list has alreedy been made for your client, you may use the words in that list. Please put " next to those words that were previously chosen.

Below is a form with blanks for your 110 words. Please put a check in the column called "Essential Words" if the word is one that must be included for daily communication. Please put a check in the column called "Extra Hords" if the word would be nice to include, but is not essential for daily communication. Different forms of the same root word (think, thought, thinking) may be listed as separate words. Please put only one word on each line. 
APPENDIX B

INFORMED CONSENT FORM 


\section{INFORMED CONSENT FORM \\ VOCABULARY NEEDS OF THE NONSPEAXING CHILD \\ AS DETERMINED BY CAREGIVERS}

.PRINCIPAL INVESTIGATOR: MELANIE FRIED-OKEN, Ph.D.

\section{DESCRIPTION OF STUDY}

Some children who have cerebral palsy cannot control their oral muscles to speak effectively. They must use communication aids to express their thoughts and needs. Many children point to pictures on communication boards or books. Others use electronic devices, such as Speak ' $n$ spell or Apple computers, that speak for a person. These aids are referred to as augmentative communication systems.

Every augmentative communication system must present words or pictures to children so that they can choose what they want to say. For example, a child must be able to point to printed words or a picture of ice cream when asked, "What do you want for dessert?"

The task of selecting the words to put on a communication board for a nonspeaking child is a very difficult one. Parents, family members, teachers and therapists must decide what words and sentences the 


\section{DESCRIPTION OF RISKS AND BENEFITS}

There are no significant risks associated with this study. You can stop anytime that you feel uncomfortable during the task. No specific benefits will be derived by participants in this study other than supplying common word lists to nonspeaking children. The results will help speech-language pathologists and adults who make communication aids select the least restrictive and most useful vocabulary for augmentative communication.

\section{CONSENT}

I have read this consent form and have discussed with Dr. Fried-Oken or her representative the procedures described above. I have been given the opportunity to ask questions, which have been answered to my satisfaction. Dr. Fried-Oken, telephone number 229-7266, has agreed to answer any questions I still might have.

I understand that as a participant in this study my identity and my medical records and data relating to this research study will be kept confidential.

It is not the policy of Good Samaritan Bospital and Medical Center, or any other agency funding the research project in which I am participating, to compensate or provide medical treatment for human subjects in the event the research results in physical injury. I should 
nonspeaking child might want (or need) to say. The vocabulary must give the child as much communication freedom as possible.

Unfortunately, most communication boards only contain between 4 and 400 words. Since you can't put every word of a language on a communication aid, most vocabulary lists are restrictive. A nonspeaking child cannot say everything he or she wants to. The problem facing adults who make communication aids for nonspeaking children is: "What words should I choose?"

The purpose of this study is to compile and compare vocabulary lists that are chosen for speaking and nonspeaking children between the ages of 3 to 6 years. The words that are commonly selected for all children will be shared with adults who make communication aids so that the nonspeaking children can be given as much communication potential as possible.

\section{PROCEDURE}

Participation in this study will involve about one hour of your time which can be in your chosen location. You will simply be asked to make a list of 100 words that your child or client would communicate. To ensure confidentiality, your name will not be used in this study. A number will replace your name so that your identity remains private. 
further understand that should I suffer any injury from the research project, compensation will be available only if I establish that the injury occurred through the faut of Good samaritan gospital, its officers or employees or my physician. Further information regarding this policy may be obtained from the office of Research Administration at 229-7218.

I understand I am free to refuse to participate or to withdraw from participation in this study at any time and it will in no way affect my relationship with, or treatment at, Good samaritan bospital and Medical Center.

I have read and understand the foregoing:

DATE 
APPENDIX C

COVER LETTER WITH INSTRUCTIONS FOR PARENTS AND CLINICIANS 


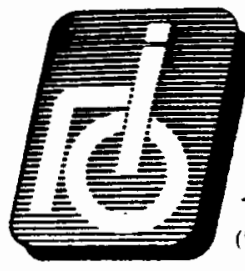

Oulpatitu Pr,gram

\section{nugagarative COMENICATION}

\section{Rebabilitation Institute of Oregon}

S03) 229.7266 1040 NW Twenty-Second : Sujte $500 \cdot$ Portand, OR 9:210

November 10,1987

\section{Dear Parent:}

I an a speech pathologist and augmentative camunication specialist at the Rehabilitation Institute of Oregon in Portland, Oregon. I provide communication services to children of all ages who have Cerebral Palsy and severe comminication impaiments.

I recently received a grant from the March of Dimes Foundation to help parents and therapists pick the first words that their nonspeaking child should use. I have contacted your child's speech pathologist or educator and asked them to help me find cooperative, energetic parents who might assist me in my work. I would like to ask you to participate in this research.

Your participation would only take 30-60 minutes of your time at hame. I will simply ask you to make a list of the 110 most important words that your child would say if he/she could taik. All you need to do is watch your child for a day or two and then make a list of the 110 most frequently needed words. Words that you have already selected for laptrays, communication boards and books, or electronic devices, may certainly be included in the 110 word 1 ist.

I will also ask your child's speech pathologist/educator to fill out a vocabulary collection form. Please do not discuss your chosen words with the therapist until you both have completed your lists. The attached informed consent form includes a more detailed description of the study. If you would like to be part of this research, please read and sign the informed consent form and complete the vocabulary collection form with words you would choose for your child.

I have enclosed a self-addressed envelope for return of the two forms. If I, or your therapist, can answer any additional questions you may have, please do not hesitate to ask. I can be reached at the above address and at 503-229-7266.

Thank you very much for your participation.

Sincerely,

Melanie Fried-Oken, Ph.D.

Research Associate in Augmentative Communication

Program Manager, Augmentative Carminication Service

MFO: sgw

Enclosures

\% Hoopital \& . Medical Center 
APPENDIX D

RESPONDENT COMPOSITE LIST 
RESPONDENT COMPOSITE LIST

Word s

Dad

Mom

Go

$S$

Drink

Play

Book

Happy

Home

He lp

More

Sad

School

Want

Car

Eat

Hot

No

Outside

Yes

Love

TV

Up

Cold

Good-Bye

You

Down

Hung ry

I

On

Cha ir

Grandma

In

Juice

Sick

Tired

Good

Grandpa

Music

Please

Potty

Bed

Coat

Come

Do

Dog

Like
Frequency

29

29

28

28

24

24

23

23

23

22

21

21

21

21

20

20

20

20

20

20

19

19

19

18

18

18

17

17

17

17

16

16

16

16

16

16

15

15

15

15

15

14

14

14

14

14

14
Word s

Me

Pants

Shoe

Sock

Stop

Thank-You

Where

Hurt

Mad

Out

sit

sleep

What

Why

Big

Bus

$\mathrm{Hi}$

Mine

Off

Read

Shirt

Toy

Baby

Bad

Ball

Cat

Friend

Table

Thirsty

Walk

Work

Bathroom

Cookie

Cracker

Cup

Eye

Hat

Little

Look

Milk

My

Under

Wash

Water

Whee lchair

Brother

Doll
Frequency

14

14

14

14

14

14

14

13

13

13

13

13

13

13

12

12

12

12

12

12

12

12

11

11

11

11

11

11

11

11

11

10

10

10

10

10

10

10

10

10

10

10

10

10

10

9 
Words

Ear

Hand

Hug

$N^{\prime} t$

Swing

Blue

Boy

Gir 1

Give

Kitchen

Leg

Nose

Peanut-Butter

Ride

Sandwich

Spoon

Swim

Teacher

When

Am

Banana

Bath

Bedroom

Cerea 1

Crayon

Food

Fruit

Have

Here

Horse

It

Make

Mou th

Not

One

Playground

Red

Talk

To

Yellow

Angry

Arm

Aunt

Bicycle

Clean

Color

Computer

Diaper

Doctor
Frequency

9

9

9

9

9

8

8

8

8

8

8

8

8

8

8

8

8

8

8

7

7

7

7

7

7

7

7

7

7

7

7

7

7

7

7

7

7

7

7

7

6

6

6

6

6

6

6

6

6
Words

Finished

Five

Game

Head

Hello

Need

Now

Open

Puzzle

Scared

Store

Telephone

Time

Unc le

Who

And

Blanket

Bread

Cousin

Feet

Four

Get

Hair

House

Is

Kiss

Know

Over

Paint

Push

Rain

Sand

Sing

Sister

Snack

Stand

That

Three

Today

Tomorrow

Turn

Two

Wet

Airplane

Al1-Done

Anima 1

App le

Birthday

Boat
Frequency

6

6

6

6

6

6

6

6

6

6

6

6

6

6

6

5

5

5

5

5

5

5

5

5

5

5

5

5

5

5

5

5

5

5

5

5

5

5

5

5

5

5

5

4

4

4

4

4

4 
Words

Can

Cheese

Comb

Dress

Fast

Floor

Footbal1

Funny

Green

Ice-Cream

Light

Listen

Lunch

Name

Okay

Pool

Pretty

Ro 11

See

Sil1y

Six

Sleepy

S1ide

slow

Sorry

Stroller

Therapist

Truck

Visit

Walker

Yesterday

Yucky

Christmas

Afraid

Again

Are

Away

Back

Basketba 11

Block

Boot

Bottom

Brace

Breakfast

Brush

By

Candy

Change

Circle

C1ose
Frequency

4

4

4

4

4

4

4

4

4

4

4

4

4

4

4

4

4

4

4

4

4

4

4

4

4

4

4

4

4

4

4

4

3

3

3

3

3

3

3

3

3

3

3

3

3

3

3

3

3

3
Words

Clothes

cloudy

Cook

Cow

Dark

Dessert

Dinner

Dirty

Eight

Exercise

Fee 1

Finger

Foot

Ful1

Glue

Hate

Hear

How

Inside

Je11y

Living-Room

Meat

Mitten

Morning

Motorcyc le

Movie

Nine

Plate

Pop

Radio

Sandbox

Seven

Shopping

Snow

Soup

Story

Swimming

Take

Tape

Teeth

Ten

The

Tummy

Van

Vegetable

Warm

Watch

White

Will

Yogurt

Yummy
Frequency 